\title{
Enantioselective $\beta$-Lactone Formation from Phenyldiazoacetates via Catalytic Intramolecular Carbon-Hydrogen Insertion
}

\author{
Michael P. Doyle,* Eric J. May \\ Department of Chemistry, University of Arizona, Tucson, Arizona 85723, USA \\ Fax +1 520 6264815; E-mail: mdoyle@u.arizona.edu \\ Received 26 January 2001
}

\begin{abstract}
Dirhodium(II) catalysts with chiral carboxylate or carboxamidate effectively promote $\beta$-lactone formation from phenyldiazoacetates in high yield and with up to $63 \%$ ee.
\end{abstract}

Key words: enantioselective carbon-hydrogen insertion, chiral dirhodium(II) catalysts, phenyldiazoacetates, $\beta$-lactones

Dirhodium(II) catalyzed intramolecular carbon-hydrogen insertion reactions originating with diazocarbonyl compounds have enjoyed wide popularity for the synthesis of cycloalkanones, lactones, and lactams. ${ }^{1-4}$ They exhibit a high preference for the formation of five-membered rings and, in the absence of conformational restrictions, ${ }^{5}$ reactivity follows the order tertiary $>$ secondary $>$ primary. ${ }^{6}$ There are few examples of insertion reactions favoring ring sizes other than five in these reactions, ${ }^{1,7-9}$ even when electronic influences would justify them. ${ }^{10}$ Recently, Davies and coworkers have demonstrated that aryldiazoacetates exhibit much higher levels of selectivity in $\mathrm{C}-\mathrm{H}$ insertion reactions. ${ }^{11}$ Based on this report and other indicators of reactivity/selectivity, ${ }^{1}$ we have searched for carbon-hydrogen insertion reactions that could provide the formation of four-membered ring $\beta$-lactones in reasonable yields and with catalyst-directed enantiocontrol.

The first substrate tested was isopropyl phenyldiazoacetate, and we were surprised to find that the corresponding $\beta$-lactone was virtually the sole product in reactions that were catalyzed by rhodium acetate and by dirhodium(II)
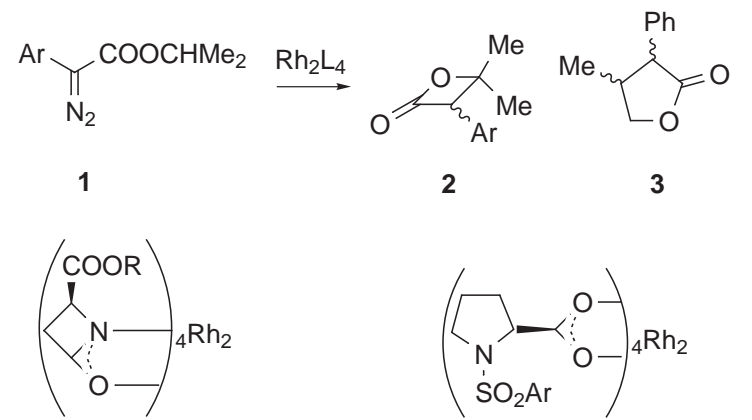

4a: $\mathrm{R}=\mathrm{Me}, \mathrm{Rh}_{2}(4 S-M E A Z)_{4}$ 4b: $\mathrm{R}={ }^{i} \mathrm{Bu}, \mathrm{Rh}_{2}(4 S-\mathrm{IBAZ})_{4}$ 4c: $\mathrm{R}=\mathrm{Bn}, \mathrm{Rh}_{2}(4 S-B N A Z)_{4}$ 4d: $\mathrm{R}=\mathrm{cC}_{6} \mathrm{H}_{11}, \mathrm{Rh}_{2}(4 S-\mathrm{CHAZ})_{4}$ 4e: $\mathrm{R}=\mathrm{CH}_{2} \mathrm{CMe}_{3}, \mathrm{Rh}_{2}(4 S-\mathrm{NEPAZ})_{4}$

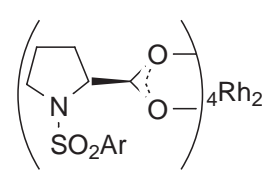

5: $\mathrm{Ar}=p-\mathrm{C}_{12} \mathrm{H}_{25} \mathrm{C}_{6} \mathrm{H}_{4}$, $\mathrm{Rh}_{2}(\mathrm{~S}-\mathrm{DOSP})_{4}$

Scheme 1 compounds 4 and 5 (Table 1). Here, insertion into the $3{ }^{\circ} \mathrm{C}-\mathrm{H}$ bond was favored over insertion into one of six $1{ }^{\circ} \mathrm{C}-\mathrm{H}$ bonds despite the additional strain introduced by formation of a four- rather than a five-membered ring. Traces of 3, mainly the trans-disubstituted lactone, were observed, but the overall difference in reactivity could be estimated to be greater than 50:1. Products were identified by spectroscopic analysis with reference to literature reports of the same compounds. ${ }^{12}$

Table 1 Enantioselectivity in Carbon-Hydrogen Insertion Reactions of Isopropyl Phenyldiazoacetate ${ }^{a}$

\begin{tabular}{lcc}
\hline catalyst & $\begin{array}{c}\text { yield, } \%^{b} \\
\mathbf{2}(\mathrm{Ar}=\mathrm{Ph})\end{array}$ & $\begin{array}{c}\text { ee, } \%^{r} \\
\mathbf{2}(\mathrm{Ar}=\mathrm{Ph})\end{array}$ \\
\hline $\mathrm{Rh}_{2}(\mathrm{OAc})_{4}$ & 84 & - \\
$\mathrm{Rh}_{2}(S-\mathrm{MEAZ})_{4}(\mathbf{4 a})$ & 83 & 33 \\
$\mathrm{Rh}_{2}(S \text {-IBAZ })_{4}(\mathbf{4 b})$ & 79 & 26 \\
$\mathrm{Rh}_{2}(S \text {-BNAZ })_{4}(\mathbf{4 c})$ & 66 & 30 \\
$\mathrm{Rh}_{2}(S \text {-CHAZ })_{4}(\mathbf{4 d})$ & 85 & 35 \\
$\mathrm{Rh}_{2}(S \text {-NEPAZ })_{4}(\mathbf{4 e})$ & 84 & 24 \\
$\mathrm{Rh}_{2}(S \text {-DOSP })_{4}(\mathbf{5})$ & 86 & 36 \\
$\mathrm{Rh}_{2}(S \text {-DOSP })_{4}(\mathbf{5})^{d}$ & 78 & 41 \\
\hline
\end{tabular}

${ }^{a}$ Reactions were performed in refluxing $\mathrm{CH}_{2} \mathrm{Cl}_{2}$, unless specified otherwise, using $1.0 \mathrm{~mol} \%$ of catalyst. ${ }^{b}$ Yield of product after separation of catalyst (up to $70 \%$ yield after chromatographic purification). ${ }^{c}$ Enantiomer separation and analyses were performed on a $25-\mathrm{cm}$, 4.6-mm $(R, R)$-WHELK-O column using 5\% EtOAc in hexanes $(8.2$ and 9.0 min for the individual enantiomers). ${ }^{d}$ Reaction performed in refluxing pentane.

Reactions catalyzed by chiral dirhodium(II) compounds, either the $\mathrm{Rh}_{2}(S \text {-DOSP })_{4}$ catalyst of Davies ${ }^{4}$ or our own chiral azetidinone-ligated catalysts, ${ }^{13,14}$ generally resulted in $\beta$-lactone product in high yield but with only modest enantioselectivities. The use of $\mathrm{Rh}_{2}(S \text {-DOSP })_{4}$ produced product with the highest $\%$ ee value, especially when the reaction was performed in pentane. Reactions with azetidinone-ligated catalysts in pentane provided no obvious advantages over reactions performed in $\mathrm{CH}_{2} \mathrm{Cl}_{2}$.

An attempt was made to determine the electronic influence of aryl substituents from aryldiazoacetates on enantiocontrol. However, significantly lower product yields were obtained with $\mathrm{Ar}=p-\mathrm{MeOC}_{6} \mathrm{H}_{4}-$ a substituent that, based on published reports by Davies, ${ }^{11,15,16}$ we thought would lead to modest changes in enantioselectivity, $\%$ ee 
values were considerably lower than those reported in Table 1 (33\% ee with 5). However, with $\mathrm{Ar}=p-\mathrm{MeC}_{6} \mathrm{H}_{4}$, $\mathrm{Rh}_{2}(S \text {-DOSP })_{4}$ gave the corresponding $\beta$-lactone in $77 \%$ yield with $48 \%$ ee, but $\mathrm{Rh}_{2}(S \text {-MEAZ })_{4}$ gave product in lower yield (34\%) and with lower enantioselectivity $(27 \%$ ee). The reason for this apparent discrepancy is as yet unresolved.

Diazo decomposition of cyclohexyl diazoacetate produces the $\gamma$-lactone products virtually exclusively. ${ }^{7}$ The corresponding $\beta$-lactone, if formed at all, is a very minor product. In contrast, diazo decomposition of cyclohexyl phenyldiazoacetate $\mathbf{6}$ gives the corresponding $\beta$-lactone product $7^{17}$ with near exclusivity (Table 2), and the catalyst had virtually no influence on regioselectivity. Here, enantioselectivities were higher than those obtained with isopropyl phenyldiazoacetate. Comparable results were obtained with cis-4-methylcyclohexyl phenyl-diazoacetate [with $\mathrm{Rh}_{2}(4 S-\mathrm{MEAZ})_{4}$ in $\mathrm{CH}_{2} \mathrm{Cl}_{2}: 74 \%$ yield, $44 \%$ ee; with $\mathrm{Rh}_{2}(S \text {-DOSP })_{4}$ in pentane: $56 \%$ yield, $44 \%$ ee].

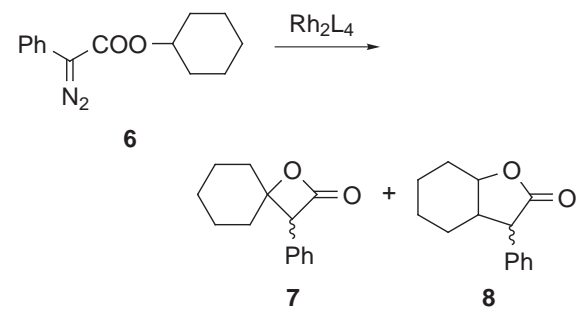

Scheme 2

Table 2 Enantioselectivity and Regioselectivity in Carbon-Hydrogen Insertion Reactions of Cyclohexyl Phenyldiazo-acetate ${ }^{a}$

\begin{tabular}{lccc}
\hline catalyst & yield, $\%^{b}$ & ee, ${ }^{c}$ & \\
\hline $\mathrm{Rh}_{2}(\mathrm{OAc})_{4}$ & 55 & - & $9: \mathbf{8}^{d}$ \\
$\mathrm{Rh}_{2}(S \text {-MEAZ })_{4}(\mathbf{4 a})$ & 67 & 50 & $98: 2$ \\
$\mathrm{Rh}_{2}(S \text {-IBAZ })_{4}(\mathbf{4 b})$ & 66 & 51 & $97: 3$ \\
$\mathrm{Rh}_{2}(S \text {-NEPAZ })_{4}(\mathbf{4 c})$ & 65 & 42 & $97: 3$ \\
$\mathrm{Rh}_{2}(S \text {-DOSP })_{4}(\mathbf{5})$ & 52 & 49 & $98: 2$ \\
$\mathrm{Rh}_{2}(S \text {-DOSP })_{4}(\mathbf{5})^{d}$ & 69 & 63 & $98: 2$ \\
\hline
\end{tabular}

${ }^{a}$ Reactions were performed as described in Table 1. ${ }^{b}$ Product yield after separation of catalyst (up to 53\% yield of $\mathbf{7}$ after chromatographic purification). ${ }^{c}$ Enantiomer separation and analyses were performed on a 25-cm, 4.6-mm (R,R)-WHELK-O column using 5\% EtOAc in hexanes (8.2 and $9.1 \mathrm{~min}$ for the individual enantiomers). ${ }^{d}$ Determined by ${ }^{1} \mathrm{H}$ NMR of unique spectral regions for $\mathbf{7}$ (ref. 17) and $\mathbf{8}$ (ref. 18). ${ }^{e}$ Reaction performed in refluxing pentane.

In each $\mathrm{C}-\mathrm{H}$ insertion reaction presented thus far the chiral center that is generated is the original diazo-carbon atom with a probable transition state orientation that is depicted in $\mathbf{9}$. When reactions of $\mathbf{1 ,} \mathbf{6}$, and their analogs $\mathrm{R}$ and $\mathrm{R}^{\prime}$ are identical and, if insertion occurs as shown in $\mathbf{9}$,

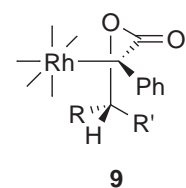

the configuration of the $\beta$-lactone product would be $R$. When $\mathrm{R}$ and $\mathrm{R}$ ' are not identical, one can expect a diastereomeric product distribution that reflects the relative stabilities of attached carbene/catalyst config-uration. This is effectually represented in results from diazo decomposition of $(S)$-(+)-2-octyl phenyldiazo-acetate (10) from which two diastereomeric $\beta$-lactone products (11 and 12) ${ }^{19}$ are formed in good yields (Table 3 ). $\gamma$-Lactone products were, at best, trace constituents of the reaction mixture. As expected, changing catalyst configurations, $\mathrm{Rh}_{2}(4 S-\mathrm{MEAZ})_{4}$ and $\mathrm{Rh}_{2}(4 R-\mathrm{MEAZ})_{4}$, resulted in modest, but measurable, differences in diastereoselection indicative of match/mismatch in catalyst-substrate interactions. Surprisingly, the 11:12 ratio with $\mathrm{Rh}_{2}(S$ DOSP $)_{4}$ was opposite to that with the $4 S$ - azetidinone-ligated dirhodium(II) catalysts, and the reason for this is unknown.

Table 3 Diastereoselectivity in Carbon-Hydrogen Insertion Reactions of $(S)$-(+)-2-Octyl Phenyldiazoacetate ${ }^{a}$

\begin{tabular}{lcc}
\hline catalyst & yield, \% & ee, \% \\
\hline $\mathrm{Rh}_{2}(\mathrm{OAc})_{4}$ & $\mathbf{1 1}^{\mathbf{1 2}}$ & $\mathbf{1 1 : 1 2}$ \\
$\mathrm{Rh}_{2}(S \text {-MEAZ })_{4}(\mathbf{4 a})$ & $91^{d}$ & $37: 63$ \\
$\mathrm{Rh}_{2}(\text {-MEAZ })_{4}($ ent-4a $)$ & 79 & $22: 78$ \\
$\mathrm{Rh}_{2}(S \text {-IBAZ })_{4}(\mathbf{4 b})$ & 60 & $53: 47$ \\
$\mathrm{Rh}_{2}(S \text {-DOSP })_{4}(\mathbf{5})^{e}$ & 68 & $36: 64$ \\
\hline
\end{tabular}

${ }^{a}$ Reactions were performed as described in Table $1 .{ }^{b}$ Yield after of removal of catalyst. ${ }^{c}$ Determined by ${ }^{1} \mathrm{H}$ NMR analysis and confirmed by GC on a SPB-5 column operated at $100{ }^{\circ} \mathrm{C} .{ }^{d}$ Column chromatography on silica (2.5-10\% EtOAc in hexanes) allowed isolation of $\mathbf{1 1}$ (28\% yield) and $\mathbf{1 2}$ (57\% yield) as separate products. ${ }^{e}$ Reaction performed in refluxing pentane.

Overall, dirhodium(II) catalysts are surprisingly selective

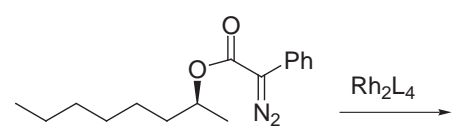

10

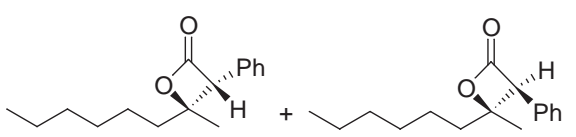

11

12

Scheme 3

for $\beta$-lactone formation, affording these products in high 
yield, although with modest enantiocontrol. However, when a tertiary $\mathrm{C}-\mathrm{H}$ bond is available that could result in a $\gamma$-lactone product, as is the case with isobutyl phenyldiazoacetate (13), only the $\gamma$-lactone product is observed (Table 4). Here use of the chiral azetidinone- ligated catalysts gave comparable\% ee values for the insertion product (14) to results from $\mathrm{Rh}_{2}(S \text {-DOSP })_{4}$ in pentane. Clearly, the presence of a tertiary $\mathrm{C}-\mathrm{H}$ bond directs $\mathrm{C}-\mathrm{H}$ insertion with phenyldiazoacetates to a far greater extent than that found with diazoacetates alone.

Table 4 Enantioselectivity in Carbon-Hydrogen Insertion Reactions of Isobutyl Phenyldiazoacetate ${ }^{\mathrm{a}}$

\begin{tabular}{lcc}
\hline catalyst & $\begin{array}{c}\text { yield, } \% \\
\mathbf{1 4}^{\boldsymbol{b}}\end{array}$ & $\begin{array}{c}\text { ee, } \% \\
\mathbf{1 4}^{\boldsymbol{c}}\end{array}$ \\
\hline $\mathrm{Rh}_{2}(\mathrm{OAc})_{4}$ & 79 & - \\
$\mathrm{Rh}_{2}(S \text {-MEAZ })_{4}(\mathbf{4 a})$ & 94 & 90 \\
$\mathrm{Rh}_{2}(S \text {-IBAZ })_{4}(\mathbf{4 b})$ & 89 & 84 \\
$\mathrm{Rh}_{2}(S \text {-DOSP })_{4}(\mathbf{5})$ & 95 & 56 \\
$\mathrm{Rh}_{2}(S \text {-DOSP })_{4}(\mathbf{5})^{d}$ & 89 & 86 \\
\hline
\end{tabular}

${ }^{a}$ Reactions were performed as described in Table $1 .{ }^{b}$ Yield after of removal of catalyst. ${ }^{c}$ Analysis on a WHELK-O column using $20 \%$ EtOAc in hexanes. ${ }^{d}$ Reaction performed in pentane.

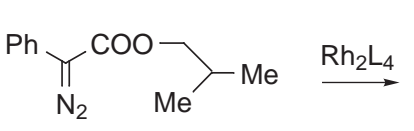

13

Scheme 4

\section{Acknowledgement}

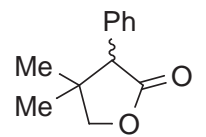

14
Support for this research from the National Science Foundation and from the National Institutes of Health (GM-46503) is gratefully acknowledged. We are grateful to Professor Huw M. L. Davies for providing us with a generous sample of $\mathrm{Rh}_{2}(S \text {-DOSP })_{4}$. This letter is dedicated to Professor Ryogi Noyori, whose insightful contributions to the development of asymmetric catalysis for metal carbene transformations has led us to fruitful discoveries.

\section{References and Notes}

(1) Doyle, M. P.; McKervey, M. A.; Ye, T. Modern Catalytic Methods for Organic Synthesis with Diazo Compounds: From Cyclopropanes to Ylides; Wiley, New York, 1998.

(2) Doyle, M. P.; McKervey, M. A. J. C. S. Chem. Commun. 1997, 983. Doyle, M. P.; Forbes, D. C. Chem. Rev. 1998, 98, 911.

(3) Padwa, A.; Austin, D. J. Angew. Chem. Int. Ed. Engl. 1994, 33, 1797. Padwa, A.; Krumpe, K. E. Tetrahedron 1992, 48, 5385.

(4) Davies, H. M. L. Eur. J. Org. Chem. 1999, 2459.

(5) Doyle, M. P.; Westrum, L. J.; Wolthuis, N. E.; See, M. M.; Boone, W. P.; Bagheri, V.; Pearson, M. M. J. Am. Chem. Soc. 1993, 115, 958.

(6) Taber, D. F.; Ruckle, R. E., Jr. J. Am. Chem. Soc. 1986, 108, 7686.

(7) Doyle, M. P.; Kalinin, A. V.; Ene, D. G. J. Am. Chem. Soc. 1996, $118,8837$.

(8) Anada, M.; Hashimoto, S. Tetrahedron Lett. 1998, 39, 79.

(9) Wee, A. G. H. Tetrahedron Lett. 2000, 41, 9025.

(10) Wang, P.; Adams, J. J. Am. Chem. Soc. 1994, 116, 3296.

(11) Davies, H. M. L.; Hansen, T.; Churchill, M. R. J. Am. Chem. Soc. 2000, 122, 3063.

(12) Imai, T.; Nichida, S. J. Org. Chem. 1979, 44, 3574.

(13) Doyle, M. P.; Zhou, Q.-L.; Simonsen, S. H.; Lynch, V. Synlett 1996, 697.

(14) Doyle, M. P.; Davies, S. B.; Hu, W. Org. Lett. 2000, 2, 1145.

(15) Davies, H. M. L.; Hansen, T.; Hopper, D.; Penaro, S. A. J. Am. Chem. Soc. 1999, 121, 6509.

(16) Davies, H. M. L.; Stafford, D. G.; Hansen, T. Org. Lett. 1999, $1,233$.

(17) Hoppe, I.; Schöllkopf, U. Liebigs Ann. Chem. 1979, 219.

(18) Black, T. H.; DuBay, W. J.; Tully, P. S. J. Org. Chem. 1988, $53,5922$.

(19) Diastereoisomers were separated, and they were identified by spectral methods; assignments were based on nOe experiments.

Article Identifier:

1437-2096,E;2001,0,SI,0967,0969,ftx,en;Y02801ST.pdf 